\title{
How does hepatic steatosis affect the outcome of patients with chronic hepatitis B?
}

\author{
Jung Hwan Yu and Jin-Woo Lee \\ Department of Internal Medicine, Inha University Hospital, Inha University School of Medicine, Incheon, Korea
}

Keywords: Fatty liver; Hepatitis B, Chronic; Treatment outcome

See Article on Page 283

Globally, the number of patients with fatty liver disease has been gradually increasing and has become a significant health care issue. 'Hepatic steatosis (HS), characterized by the buildup of fat in the liver, is closely associated with metabolic disease and may progress to liver cirrhosis and hepatocellular carcinoma (HCC). With the increasing prevalence of HS, interest in the effects of HS on other diseases such as hepatitis $B$, is also increasing. Particularly, in hepatitis B virus-endemic areas such as Korea, one of the important issues is how HS affects the prognosis and development of HCC in patients with chronic hepatitis B (CHB).

To date, various studies on the interaction between HS and hepatitis B virus (HBV) have been conducted. Based on a study of 3,212 patients with CHB in Asia, this paper showed an inverse association between HBV virological factor and degree of $\mathrm{HS}^{2}$ Particularly, the amount of hepatitis B surface antigen ( $\mathrm{HBsAg}$ ) in the liver notably decreased as HS progressed. Besides, some papers have reported that viral replication decreased in patients with $\mathrm{CHB}$ with $\mathrm{HS}^{3}$ and HBV may play a protective effect on the devel- opment of fatty liver. ${ }^{4}$ In contrast, studies have reported an increased rate of non-alcoholic fatty liver disease (NAFLD) in patients with HBV. ${ }^{5,6}$ Moreover, some experimental studies reported that hepatitis $B$ virus $X$ protein has a role in increasing the development of HS by regulating several transcription factors such as sterol regulatory element-binding protein-1c, and peroxisome proliferator-activated receptor. ${ }^{7,8}$ However, due to the different results of clinical studies, it is still not enough to clearly define the relationship between HS and HBV, and more reliable and well-designed studies are needed to confirm this.

Few studies reported on the effect of HS on the outcome of antiviral therapy (AVT) in patients with CHB. In one recent study performed in 145 patients with CHB who were administered entecavir (ETV) or tenofovir (TDF), HS had no impact on the virologic response to ETV and TDF treatment. ${ }^{9}$ In contrast, other studies in China reported that HS was significantly associated with ETV treatment failure and suggested a specified antiviral strategy in patients with $\mathrm{CHB}$ with $\mathrm{HS}^{4}{ }^{4}$ In this study, 267 Chinese patients with CHB treated with ETV were analyzed, and HS was an independent factor of ETV treatment failure in multivariate logistic regression at 24, 48, and 96 weeks. Moreover, HBV-DNA clearance

\section{Abbreviations:}

AVT, antiviral therapy; CAP, controlled attenuated parameter; CHB, chronic hepatitis B; ETV, entecavir; HBeAg, hepatitis B e antigen; HBsAg, hepatitis B surface antigen; HBV, hepatitis B virus; HCC, hepatocellular carcinoma; HS, hepatic steatosis; NAFLD, non-alcoholic fatty liver disease; TDF, tenofovir

\section{Corresponding author : Jin-Woo Lee}

Department of Internal Medicine, Inha University Hospital, 27 Inhang-ro, Jung-gu, Incheon 22332, Korea

Tel: +82-32-890-2548, Fax: +82-32-882-6578

E-mail: jin@inha.ac.kr

https://orcid.org/0000-0002-7227-4938

Received: Dec. 3, 2018/ Accepted : Dec. 10, 2018

Copyright $\odot 2019$ by Korean Association for the Study of the Live

This is an Open Access article distributed under the terms of the Creative Commons Attribution Non-Commercial License (http://creativecommons.org/licenses/by-nc/3.0/) which permits unrestricted non-commercial use, distribution, and reproduction in any medium, provided the original work is properly cited. 
and hepatitis B e antigen (HBeAg) seroconversion were both lower throughout the follow-up in patients with $\mathrm{CHB}$ with $\mathrm{HS} .{ }^{4}$ Furthermore, a recent meta-analysis study showed that the efficacy of AVT declined in patients with CHB with $\mathrm{HS} .{ }^{10}$ This meta-analysis study suggested that virological and biochemical responses were significantly different between the subgroups with and without HS. This might be explained by the decreased bioavailability of AVT due to fatty changes, leading to a significant loss in contact area between hepatocytes and antiviral agents.

Recently, several animal experimental studies have investigated the relationship between HBV replication and HS. In one study using transgenic mice with HBV replication DNA, mice fed on highfat diet showed a significant decline in the levels of HBV-DNA, HBeAg, HBsAg, hepatitis B core antigen, and HBV pregenome RNA compared with those fed a normal diet, but this animal model did not provide the mechanistic details by which HS prevents HBV replication." Based on other animal studies, HS seems to either lead to cytoplasmic distribution of HBsAg or hepatocyte cell death, thereby leading to seroclearance of $\mathrm{HBV}^{12}$ Another experimental study reported that intestinal microbial imbalance can activate liver immunity and HBV clearance. ${ }^{13}$ It is quite possible that the change of gut microbiota associated with HS has a role in HBV clearance, which needs to be validated.

The association between development of $\mathrm{HCC}$ and $\mathrm{HS}$ in patients with CHB is still unclear. In a recent study reported in Korea, HBV was the most common (65.5\%) cause of HCC, and the overall rate of NAFLD-associated HCC was $4.7 \% .^{14}$ However, the number of patients with HBV-related HCC with $\mathrm{HS}$ and how it affects the development of HCC in patients with CHB is unknown. In the current issue, Kim et al. also did not show a significant association between HS and liver fibrosis, and controlled attenuated parameter (CAP) value did not influence the risk of HCC development. ${ }^{15} \mathrm{~A}$ recent study by Seto et al. showed a significant correlation between the degree of stiffness and HS assessed using transient elastography. ${ }^{16}$ However, other studies did not show any correlation between $\mathrm{HS}$ and fibrosis in patients with CHB and showed a decreasing pattern in advanced stage of NAFLD. Thus, the exact association between steatotic burden and risk of HCC development remained unclear, and more research is needed.

Liver biopsy is the gold standard in the diagnosis of HS; however, it is not usually performed because of procedure-induced complication and inconvenience to patients. Furthermore, liver biopsy can result in sampling errors due to uneven fat distribution in the liver and has a disadvantage that it is difficult to perform because of repeated monitoring following a therapeutic intervention.
Nowadays, several imaging techniques provide reliable non-invasive alternatives to evaluate HS. Measurement of liver fat content by magnetic resonance imaging-derived proton density fat fraction is perhaps the most accurate method among non-invasive techniques; however, it is expensive and may not be available in all imaging centers. ${ }^{17}$ In contrast, the CAP from Fibroscan (Echosens, Paris, France) can overcome these disadvantages at least partially and also has several advantages in evaluating HS. First, CAP value can detect liver stiffness and HS from the same region of interest. Second, this technique has a well-defined quality criteria and good reproducibility. Therefore, it is expected to be widely used as a method to evaluate $\mathrm{HS}$ in various studies.

Although there is a substantial limitation that CAP value does not represent the whole liver in patients with CHB with $\mathrm{HS}$, this study was an effort to determine the influence of $\mathrm{HS}$ on $\mathrm{CHB}$ and provides an impact on above concerns in patients with CHB undergoing antiviral treatment based on the current guideline. Despite the results of this study, many challenges remain to reveal the association between HS and HBV prognosis. Data regarding the effect of lean nonalcoholic steatohepatitis in patients with CHB, mainly observed in Asians, are unavailable. Therefore, further research is needed to clarify its clinical implications.

\section{Authors' contribution}

Manuscript writing: Jung Hwan Yu and Jin-Woo Lee

Final approval of manuscript: Jung Hwan Yu and Jin-Woo Lee

\section{Conflicts of Interest}

The authors have no conflicts to disclose.

\section{REFERENCES}

1. Oh H, Jun DW, Saeed WK, Nguyen MH. Non-alcoholic fatty liver diseases: update on the challenge of diagnosis and treatment. Clin Mol Hepatol 2016;22:327-335.

2. Wang MM, Wang GS, Shen F, Chen GY, Pan Q, Fan JG. Hepatic steatosis is highly prevalent in hepatitis B patients and negatively associated with virological factors. Dig Dis Sci 2014;59:2571-2579.

3. Wong VW, Wong GL, Chu WC, Chim AM, Ong A, Yeung DK, et al. Hepatitis $B$ virus infection and fatty liver in the general population. J Hepatol 2012;56:533-540.

4. Machado MV, Oliveira AG, Cortez-Pinto H. Hepatic steatosis in hepatitis $B$ virus infected patients: meta-analysis of risk factors and comparison with hepatitis C infected patients. J Gastroenterol Hepatol 2011;26:1361-1367. 
5. Sass DA, Chang P, Chopra KB. Nonalcoholic fatty liver disease: a clinical review. Dig Dis Sci 2005;50:171-180.

6. Peng XE, Chen FL, Wu YL, Lu QQ, Chen WN, Xu L. The roles of HBV infection and host factors in ultrasound-diagnosed fatty liver: a case-control study. Hepatogastroenterology 2013;60:1698-1704.

7. Kim KH, Shin HJ, Kim K, Choi HM, Rhee SH, Moon HB, et al. Hepatitis $B$ virus $X$ protein induces hepatic steatosis via transcriptional activation of SREBP1 and PPARgamma. Gastroenterology 2007;132:1955-1967.

8. Kim K, Kim KH, Kim HH, Cheong J. Hepatitis B virus X protein induces lipogenic transcription factor SREBP1 and fatty acid synthase through the activation of nuclear receptor LXRalpha. Biochem J 2008;416:219-230.

9. Ceylan B, Arslan F, Batırel A, Fincancı M, Yardımcı C, Fersan E, et al. Impact of fatty liver on hepatitis $B$ virus replication and virologic response to tenofovir and entecavir. Turk J Gastroenterol 2016;27:4246.

10. Zhu Y, Yang Q, Lv F, Yu Y. The effect of hepatosteatosis on response to antiviral treatment in patients with chronic hepatitis B: a metaanalysis. Gastroenterol Res Pract 2017;2017:1096406.

11. Hu D, Wang H, Wang H, Wang Y, Wan $X$, Yan W, et al. Nonalcoholic hepatic steatosis attenuates hepatitis $B$ virus replication in an HBV-immunocompetent mouse model. Hepatol Int 2018;12:438446.

12. Zhang Z, Pan Q, Duan XY, Liu Q, Mo GY, Rao GR, et al. Fatty liver reduces hepatitis $B$ virus replication in a genotype $B$ hepatitis $B$ virus transgenic mice model. J Gastroenterol Hepatol 2012;27:1858-1864.

13. Chou HH, Chien WH, Wu LL, Cheng $\mathrm{CH}$, Chung $\mathrm{CH}_{\text {, Horng JH, et }}$ al. Age-related immune clearance of hepatitis $B$ virus infection requires the establishment of gut microbiota. Proc Natl Acad Sci U S A 2015;112:2175-2180.

14. Yoon CH, Jin YJ, Lee JW. Nonalcoholic fatty liver disease-associated hepatocellular carcinoma in a hepatitis B virus-endemic area. Eur J Gastroenterol Hepatol 2018;30:1090-1096.

15. Kim DS, Jeon MY, Lee HW, Kim BK, Park JY, Kim DY, et al. Influence of hepatic steatosis on the outcomes of patients with chronic hepatitis B treated with entecavir and tenofovir. Clin Mol Hepatol 2019;25:283-293.

16. Seto WK, Hui RWH, Mak LY, Fung J, Cheung KS, Liu KSH, et al. Association between hepatic steatosis, measured by controlled attenuation parameter, and fibrosis burden in chronic hepatitis B. Clin Gastroenterol Hepatol 2018;16:575-583.e2.

17. Lee DH. Imaging evaluation of non-alcoholic fatty liver disease: focused on quantification. Clin Mol Hepatol 2017;23:290-301. 